\title{
Cardiorenal Determinants of Erectile Dysfunction in Primary Prevention: A Cross-Sectional Study
}

\author{
Vilma Dzenkeviciute $e^{a, c, d} \quad$ Zaneta Petrulioniene ${ }^{b-d}$ Egidija Rinkuniene ${ }^{c, d}$ \\ Virginijus Sapoka ${ }^{a, c, d}$ Marija Petrylaite ${ }^{c}$ Jolita Badariene ${ }^{b-d}$ \\ ${ }^{a}$ Clinic of Internal Medicine, Oncology and Family Medicine and ${ }^{b}$ Clinic of Heart and Vascular Medicine, \\ 'Faculty of Medicine, Vilnius University, and d Vilnius University Hospital Santaros Klinikos, Vilnius, Lithuania
}

\section{Significance of the Study}

- In this study, left ventricular hypertrophy and kidney dysfunction were independent risk factors for severe erectile dysfunction (ED). However, the significance of carotid plaques or total cardiovascular risk was not confirmed. Hence, the presence of ED could be associated with not only vascular function, but also chronic myocardial injury, such as hypertrophy, or kidney dysfunction. Therefore, ED could be a marker for cardiovascular disease and indicate the need to take preventive measures.

\section{Keywords}

Erectile dysfunction - Cardiovascular risk score .

Echocardiography · Left ventricular hypertrophy · Target organ damage

\begin{abstract}
Objective: The aim of this study was to investigate the association between the severity of erectile dysfunction (ED), cardiovascular risk, and target organ damage (heart, renal, vascular) in men free of cardiovascular diseases (CVD). Subjects and Methods: ED was assessed using the International Index of Erectile Function (IIEF-5). The study included 182 men: 100 with ED (IIEF mean score $\leq 21$ ) and 82 without ED (IIEF mean score $>21$ ). Ultrasound was used to evaluate carotid plaques and left ventricular mass, geometry, and diastolic function. Cardiovascular anamnesis, CVD risk factors, and anthropo-
\end{abstract}

\section{KARGER}

E-Mail karger@karger.com www.karger.com/mpp

\section{The Author(s) \\ Published by S. Karger AG, Basel \\ Karger \\ Open access}

This is an Open Access article licensed under the Creative Commons Attribution-NonCommercial-4.0 International License (CC BY-NC) (http://www.karger.com/Services/OpenAccessLicense), applicable to the online version of the article only. Usage and distribution for commercial purposes requires written permission. metric and biochemical parameters were obtained. The European Society of Cardiology-Systematic Coronary Risk Evaluation Score (ESC-SCORE) was used to calculate total patient cardiovascular risk. Continuous variables between groups were compared using the Student $t$ test and Mann-Whitney $\mathrm{U}$ test, while categorical data were compared using the $\mathrm{X}^{2}$ test. Multiple linear regression was used to test the association between the severity of ED and presence of target organ damage. Results: The following parameters were significantly higher in the ED group compared to the controls: family history of coronary heart disease (43.7 vs. $26.7 \%, p=$ $0.047)$, ESC-SCORE $(2.27 \pm 1.79$ vs. $1.61 \pm 1.13, p=0.012)$, and waist circumference (109.28 \pm 10.82 vs. $106.17 \pm 10.07, p=$ 0.047). Impaired renal function ( $p=0.081)$, albuminuria ( $p=$ $0.545)$, vascular damage $(p=0.602)$, and diastolic function $(p=0.724)$ were similar in both groups. However, left ventricular hypertrophy (LVH; odds ratio $2.231,95 \%$ Cl 1.069 - 
$4.655, p=0.22$ ) was more frequent in the ED group (29.9 vs. $16.0 \%)$. The multiple linear regression analysis revealed that $\mathrm{LVH}(\beta=1.761, p=0.002)$ and impaired renal function assessed using the estimated glomerular filtration rate $(<60$ $\mathrm{mL} / \mathrm{min} / 1.73 \mathrm{~m}^{2} ; \beta=6.207, p=0.0001$ ) were the independent risk factors for severity of ED. Conclusion: This study showed that LVH and impaired renal function are associated with ED severity.

(C) 2017 The Author(s)

Published by S. Karger AG, Basel

\section{Introduction}

Erectile dysfunction (ED) is a clinical marker of a vascular disease in high-risk patients. Risk factors for ED include hypertension [1], diabetes mellitus [2], cardiovascular disease (CVD) [3], metabolic syndrome (MS) [4], tobacco use [5], hyperlipidemia [6], hypogonadism [7], lower urinary tract symptoms [8], and depression [9]. However, the multiethnic study of atherosclerosis (MESA) showed ED to be an independent predictor of CVD events [10].

Left ventricular hypertrophy $(\mathrm{LVH})$ is associated with increased risk of major cardiovascular events and allcause mortality; it may also be an independent predictor of morbid cardiovascular events [11]. Renal dysfunction, either defined by urine albumin excretion or estimated glomerular filtration rate (eGFR), or both, also predicts a heightened cardiovascular risk $[12,13]$. All these conditions are associated with diabetes [14], myocardial infarction [15], hypercholesterolemia [16], valvar stenotic and regurgitate lesions [17], as well as African American ethnicity [18].

The temporal relationship between subclinical CVD that may precede overt clinical CVD and target organ damage by longer than a decade, and the onset of ED remains poorly described [12-17]. Therefore, in this study, the goal was to evaluate which parameters of target organ damage or subclinical vascular disease had the strongest relationship with ED severity.

\section{Subjects and Methods}

\section{Study Participants}

The study was conducted at the Outpatient Preventive Cardiology Clinic, Vilnius University Hospital Santaros Klinikos, Lithuania. The study population consisted of 182 Caucasian primary prevention subjects. The inclusion criteria were the presence of cardiovascular risk factors, and the ability to read and understand

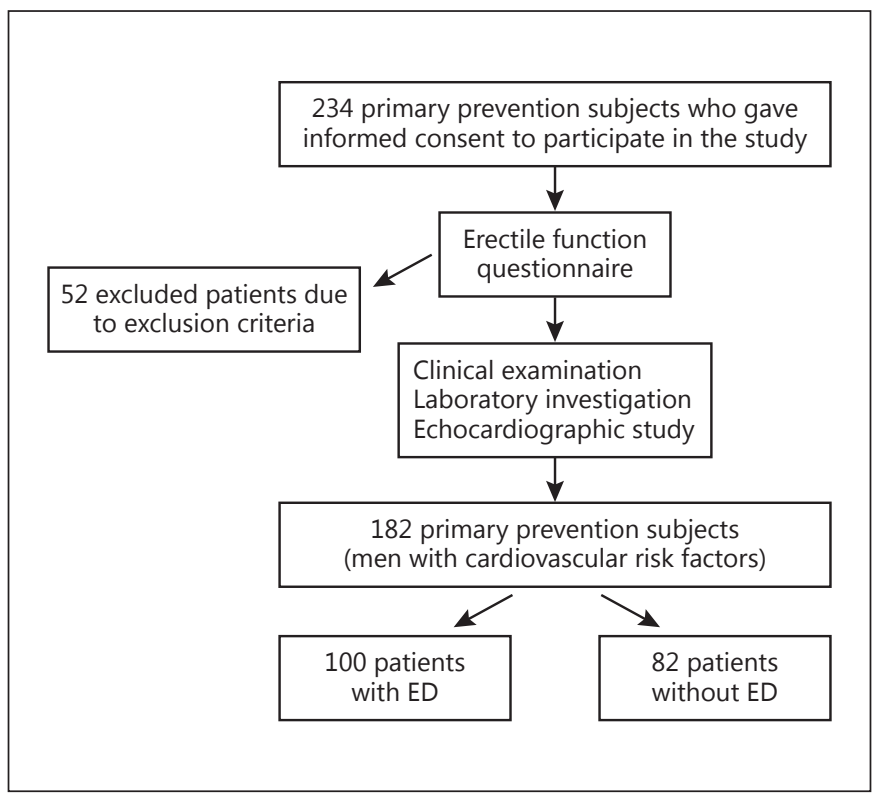

Fig. 1. Flow chart of the study population.

the study and the associated questions (Fig. 1). Patients either married or currently in a stable relationship with a partner and who were sexually active were enrolled in this study.

Written informed consent was obtained from all participants and the protocol was approved by the Institutional Review Board. Demographic data were collected from the patients, as well as a complete medical, surgical, and psychosexual history. A detailed physical examination and biochemical tests were performed. The International Index of Erectile Function (IIEF) questionnaire was used to evaluate erectile function. Participants were assigned to either of the 2 study groups based on their IIEF scores.

\section{Study Design}

In this cross-sectional study all measurements were performed in the morning between 8:00 and 11:00 a.m. Participants were requested to abstain from tobacco, coffee, and food for at least $12 \mathrm{~h}$. Any vasoactive medication intake was to be discontinued for at least $24 \mathrm{~h}$ before the study.

Height in meters, weight in kilograms, and waist circumference in centimeters were measured. Waist circumference was measured with a measuring tape at the midpoint between the bottom of the rib cage and the top of the iliac crest, in a standing position, with the subject breathing normally. The body mass index was also calculated (as $\left.\mathrm{kg} / \mathrm{m}^{2}\right)$.

Blood pressure (BP) measurements were performed with subjects in a seated position following a 10-min resting period. Two consecutive measurements of $\mathrm{BP}$ and heart rate were obtained and the average of the 2 measurements was recorded.

Information about traditional cardiovascular risk factors was collected from patient anamnesis, physical examination, and medical history. Hypertension was defined as any systolic BP $\geq 140 \mathrm{~mm}$ $\mathrm{Hg}$ and/or diastolic BP $\geq 90 \mathrm{~mm} \mathrm{Hg}$, or a history of antihypertensive medication use. Current smoking was defined as any cigarette smoking during the past month. 
Table 1. Baseline characteristics of the patients

\begin{tabular}{lccl}
\hline & $\begin{array}{l}\text { ED } \\
(n=100)\end{array}$ & $\begin{array}{l}\text { ED }- \\
(n=82)\end{array}$ & $p$ value \\
\hline IIEF score & $18.30 \pm 2.91$ & $23.41 \pm 1.04$ & $0.0001^{*}$ \\
Age, years & $47.28 \pm 3.96$ & $46.33 \pm 4.37$ & 0.132 \\
BMI & $31.96 \pm 4.49$ & $30.79 \pm 4.07$ & 0.068 \\
WC, cm & $109.28 \pm 10.82$ & $106.17 \pm 10.07$ & $0.047^{*}$ \\
ESC-SCORE & $2.27 \pm 1.79$ & $1.61 \pm 1.13$ & $0.012^{*}$ \\
Systolic BP, mm Hg & $138.78 \pm 13.58$ & $135.68 \pm 13.51$ & 0.145 \\
Diastolic BP, mm Hg & $88.91 \pm 9.29$ & $87.48 \pm 9.17$ & 0.321 \\
MAP, mm Hg & $105.33 \pm 10.43$ & $102.64 \pm 10.70$ & 0.151 \\
Fasting glucose, mmol/L & $6.26 \pm 1.29$ & $6.28 \pm 1.75$ & 0.954 \\
\hline Total cholesterol, mmol & $6.39 \pm 1.52$ & $6.36 \pm 1.22$ & 0.896 \\
LDL cholesterol, mmol/L & $3.99 \pm 1.38$ & $3.98 \pm 1.11$ & 0.973 \\
HDL cholesterol, mmol/L & $1.22 \pm 1.21$ & $1.16 \pm 0.29$ & 0.605 \\
TG, mmol/L & $3.10 \pm 3.13$ & $2.61 \pm 1.92$ & 0.192 \\
CRP, mg/L & $3.21 \pm 3.09$ & $3.71 \pm 7.39$ & 0.572 \\
Urine albumin, mg/L & $19.64 \pm 65.15$ & $15.33 \pm 39.40$ & 0.637 \\
Urine creatinine, mmol/L & $13.38 \pm 5.32$ & $14.47 \pm 6.40$ & 0.290 \\
ACR & $1.38 \pm 3.75$ & $1.05 \pm 2.58$ & 0.555 \\
Serum creatinine, $\mu$ mol/L & $79.70 \pm 12.69$ & $81.02 \pm 10.73$ & 0.516 \\
eGFR, mL/min/1.73m ${ }^{2}$ & $86.99 \pm 8.13$ & $88.24 \pm 4.87$ & 0.285 \\
\hline
\end{tabular}

Data are presented as the mean \pm SD. ED+, with erectile dysfunction; ED-, control group without erectile dysfunction; IIEF, International Index of Erectile Function; BMI, body mass index; WC, waist circumference; CV, cardiovascular; ESC-SCORE, the European Society of Cardiology-Systematic Coronary Risk Evaluation Score; BP, blood pressure; MAP, mean arterial pressure; LDL, low-density lipoprotein; HDL, high-density lipoprotein; TG, triglycerides; CRP, C-reactive protein; ACR, albumin to creatinine ration; eGFR, glomerular filtration rate.
The diagnosis of MS was based on the 2005 modified criteria of the National Cholesterol Education Program (NCEP) Adult Treatment Panel III (ATP III). Three or more of the following factors had to be present: hypertension $\geq 140 \mathrm{~mm} \mathrm{Hg}$, waist circumference $\geq 102 \mathrm{~cm}$, serum triglycerides $(\mathrm{TG}) \geq 1.7 \mathrm{mmol} / \mathrm{L}$, high-density lipoprotein cholesterol $<1 \mathrm{mmol} / \mathrm{L}$, and fasting glucose $\geq 5.6$ $\mathrm{mmol} / \mathrm{L}$.

\section{International Index of Erectile Function}

Patients were screened for the presence of ED using the validated IIEF questionnaire. A score $<21$ (out of a total of 25 points) was used as a threshold value for the diagnosis of ED. At this cut-off point the test has a sensitivity of 98 and a specificity of $88 \%$ [19]. The analysis focused on 2 groups: patients with an IIEF- 5 score $>21$ (without ED, the control group) and with an IIEF-5 score $\leq 21$ (the ED group).

\section{Echocardiographic Examination}

Echocardiography was performed with participants lying in a supine position and turned to their left side at a $30^{\circ}$ angle. An echocardiography machine with a $2.5-\mathrm{MHz}$ transducer (GE Systems, Oslo, Norway) was used to obtain 2-dimensional guided M-Mode echocardiograms at chord level just below the mitral valves. Septal and posterior wall thickness as well as left ventricular chamber dimensions were measured following the American Society of Echocardiography (ASE) guidelines. The left ventricle mass index (LVMI) was calculated using the ASE-recommended formula:

\section{LVMI $\left(\mathrm{g} / \mathrm{m}^{2}\right)=\left(1.04\left[(\mathrm{IVST}+\mathrm{LVID}+\mathrm{PWT})^{3}-\mathrm{LVID}^{3}\right]-\right.$ 13.6)/body surface area,}

where IVST is the interventricular septal thickness, LVID is the left ventricle internal dimension, and PWT is the posterior wall thickness.

LVH is defined as LVMI $\geq 95 \mathrm{~g} / \mathrm{m}^{2}$ in females and $\geq 115 \mathrm{~g} / \mathrm{m}^{2}$ in males. Diastolic dysfunction was evaluated by septal and lateral $\mathrm{E}$, and the left atrial volume according to the EAE/ASE Recommendations for the Evaluation of Left Ventricular Diastolic Function by Echocardiography [20].

Fasting glucose and lipids (total cholesterol [TC], high-density lipoprotein-cholesterol [HDL-C], and TG), C-reactive protein, as well as serum creatinine were measured using the Cobas 8,000 modular analyzer series (Roche Diagnostics, Vienna, Austria). Low-density lipoprotein-cholesterol (LDL-C) was calculated using the Friedewald formula: LDL-C = TC - HDL-C - TG/2.2. The eGFR was calculated from the serum creatinine level standardized to an isotope dilution mass spectrometry using the chronic kidney disease epidemiology collaboration equation [21]. The urine albumin to creatinine ratio (ACR) was calculated in milligrams of albumin per millimole of creatinine $(\mathrm{mg} / \mathrm{mmol})$. Kidney damage was considered present with $\mathrm{ACR} \geq 3$ and a decreased GFR with $\mathrm{eGFR}<60 \mathrm{~mL} / \mathrm{min} / 1.73 \mathrm{~m}^{2}$. 
Table 2. Values of target organ damage markers according to ED

\begin{tabular}{lccc}
\hline & $\begin{array}{l}\text { ED }+ \\
(n=86)\end{array}$ & $\begin{array}{l}\text { ED- } \\
(n=82)\end{array}$ & $p$ value \\
\hline Kidney dysfunction (eGFR <60) & $5.8(5)$ & 0 & 0.081 \\
ACR $\geq 3$ & $1.16(1)$ & 0 & 0.545 \\
Plaques in carotid arteries (total score) & $45.34(39)$ & $39.03(32)$ & 0.306 \\
ABI $<0.9$ & $4.65(4)$ & $3.65(3)$ & 0.586 \\
LVH $\geq 115$ g/m & $29.01(29)$ & $15.85(13)$ & 0.022 \\
Diastolic dysfunction & $21(18)$ & $23.2(19)$ & 0.431 \\
\hline
\end{tabular}

Data are presented as \% (n). ED+, with erectile dysfunction; ED-, control group without erectile dysfunction; eGFR, estimated glomerular filtration rate; ACR, albumin to creatinine ratio; $\mathrm{ABI}$, ankle brachial index; LVH, left ventriclular hypertrophy.

\section{Statistical Analysis}

Data were analyzed using the Statistical Package for the Social Sciences (SPSS) 16.0 (version for Windows). Values of quantitative variables were expressed as frequencies or means \pm standard deviation (SD).

Differences between the ED groups were tested using the Student $t$ test for normally distributed variables and the Mann-Whitney $U$ test for abnormally distributed continuous variables, while categorical data were compared using the $\chi^{2}$ test. The Pearson correlation was used to associate target organ damage parameters with the IIEF score.

Forward stepwise models of linear multiple regression were used to test the association between the severity of ED and impaired renal function (eGFR $<60 \mathrm{~mL} / \mathrm{min} / 1.73 \mathrm{~m}^{2}$ ), albuminuria $(\mathrm{ACR} \geq 3)$, diastolic dysfunction, carotid plaques, $\mathrm{LVH}$, and $\mathrm{MS}$ as independent variables. In all tests, a $p$ value $<0.05$ was statistically significant.

Multiple linear regression analysis models were used to evaluate possible independent risk factors influencing the severity of ED. The multivariate model consisted of the IIEF score as the dependent variable, and impaired renal function (eGFR $<90 \mathrm{~mL} / \mathrm{min}$ per $1.73 \mathrm{~m}^{2}$ ), albuminuria (ACR $\geq 3$ ), diastolic dysfunction, carotid plaques, $\mathrm{LVH}$, and $\mathrm{MS}$ as independent variables.

\section{Results}

The mean age of the population was $47.5 \pm 3.4$ years. Of the 182 patients, ED was diagnosed as mild in $79(43.4 \%)$, mild to moderate in 17 (9.3\%), moderate in $3(1.6 \%)$, and severe $1(0.5 \%)$. Men with ED had a significantly higher cardiovascular risk and prevalence of family history of coronary heart disease than those in the control group. No significant differences were found regarding smoking, diabetes mellitus, obesity, duration of obesity, MS, or hypertension between the ED patients and controls. The baseline features of both groups are presented in Table 1.

Values of target organ damage markers were similar in both groups except for LVH (29 [29.9\%] in the ED group vs. 13 [16.0\%] in the control group, $p=0.022$; Table 2). The odds ratio for LVH was 2.231 (95\% CI 1.069-4.655, $p=0.022)$ in the ED group.

Univariate analysis showed a significant isolated association between the IIEF score and ACR $(r=-0.149, p=$ $0.015)$ and left ventricular myocardial mass index $(r=$ $-0.139, p=0.008)$. No association was found between the IIEF score and carotid plaques $(r=-0.057, p=0.516)$, $\operatorname{eGFR}(r=-0.021, p=0.815), \mathrm{MS}(r=0.0408, p=0.543)$, or ankle brachial index $(r=-0.07, p=0.516)$.

The echocardiographic parameters are summarized in Table 3. No significant difference was observed between the groups regarding diastolic dysfunction $(21.0 \%$ [ $n=$ $21]$ in the ED group vs. $23.2 \%[n=19]$ in the control group, $p=0.724$ ). Only the $\mathrm{E} / \mathrm{E}$ 'septal ratio was significantly different between the groups (11.45 \pm 3.45 in the ED group vs. $10.24 \pm 3.50$ in the control group, $p=0.046$ ). When all variables were assessed concurrently for influencing ED severity, only LVH $(\beta=1.761, p=0.002)$ and impaired renal function $(\beta=6.207, p=0.0001)$ were identified as independent predictors (Table 4 ).

\section{Discussion}

In this study, the severity of ED was associated with $\mathrm{LVH}$ and impaired renal function. The finding that ED was associated with ventricular hypertrophy confirmed the study of Kakkavas et al. [22] in which it was reported that ED was associated with left ventricular diastolic dysfunction, which is an early abnormality in the evolution of hypertensive LVH. Heikkilä et al. [23] found a U-shaped correlation between ED and diastolic BP, which confirms the link between ED and severity of hypertension. ED and hypertension share a common pathogenesis, namely vas- 
Table 3. Echocardiography variables related to ED

\begin{tabular}{|c|c|c|c|}
\hline & $\begin{array}{l}\mathrm{ED}+ \\
(n=100)\end{array}$ & $\begin{array}{l}\text { ED- } \\
(n=82)\end{array}$ & $p$ value \\
\hline \multicolumn{4}{|l|}{ Cardiac chamber diameters } \\
\hline Aorta, $\mathrm{cm}$ & $3.36 \pm 0.36$ & $3.25 \pm 0.34$ & 0.060 \\
\hline Left atrium, $\mathrm{cm}$ & $3.97 \pm 0.43$ & $3.92 \pm 0.43$ & 0.521 \\
\hline Left atrial index, $\mathrm{cm} / \mathrm{m}^{2}$ & $1.84 \pm 0.19$ & $1.79 \pm 0.20$ & 0.173 \\
\hline Left atrial volume, $\mathrm{mL}$ & $69.08 \pm 19.00$ & $65.44 \pm 13.55$ & 0.197 \\
\hline Left atrial volume index, $\mathrm{mL} / \mathrm{m}^{2}$ & $32.26 \pm 8.88$ & $29.79 \pm 5.84$ & 0.054 \\
\hline LVSD, $\mathrm{cm}$ & $3.31 \pm 0.48$ & $3.35 \pm 0.48$ & 0.727 \\
\hline LVDD, $\mathrm{cm}$ & $5.23 \pm 0.47$ & $5.15 \pm 0.48$ & 0.334 \\
\hline Left ventricular index, $\mathrm{cm} / \mathrm{m}^{2}$ & $2.42 \pm 0.21$ & $2.36 \pm 0.28$ & 0.130 \\
\hline Right ventricle, $\mathrm{cm}$ & $2.71 \pm 0.32$ & $2.63 \pm 0.30$ & 0.166 \\
\hline LVEF, \% & $54.93 \pm 0.58$ & $54.92 \pm 0.64$ & 0.892 \\
\hline \multicolumn{4}{|l|}{ Left ventricular hypertrophy } \\
\hline RWT & $0.45 \pm 0.30$ & $0.40 \pm 0.06$ & 0.189 \\
\hline Septum thickness in systole, $\mathrm{cm}$ & $1.47 \pm 0.25$ & $1.42 \pm 0.24$ & 0.397 \\
\hline Septum thickness in diastole, $\mathrm{cm}$ & $1.09 \pm 0.11$ & $1.04 \pm 0.14$ & $0.021^{*}$ \\
\hline PWT in systole, $\mathrm{cm}$ & $1.52 \pm 0.29$ & $1.45 \pm 0.28$ & 0.323 \\
\hline PWT in diastole, $\mathrm{cm}$ & $2.51 \pm 12.31$ & $1.03 \pm 0.14$ & 0.307 \\
\hline LVMI, g/m² & $102.42 \pm 20.50$ & $94.93 \pm 21.67$ & $0.02 *$ \\
\hline LAVI, $\mathrm{mL} / \mathrm{m}^{2}$ & $32.26 \pm 8.88$ & $29.79 \pm 5.84$ & 0.054 \\
\hline \multicolumn{4}{|l|}{ Diastolic function } \\
\hline E wave velocity, $\mathrm{m} / \mathrm{s}$ & $0.78 \pm 0.15$ & $0.76 \pm 0.18$ & 0.425 \\
\hline A wave velocity, $\mathrm{m} / \mathrm{s}$ & $0.74 \pm 0.13$ & $0.70 \pm 0.15$ & 0.145 \\
\hline E wave deceleration time, $\mathrm{m} / \mathrm{s}$ & $246.09 \pm 99.97$ & $242.30 \pm 97.85$ & 0.824 \\
\hline $\mathrm{E} / \mathrm{A}$ ratio, $\mathrm{m}$ & $1.09 \pm 0.30$ & $1.11 \pm 0.32$ & 0.621 \\
\hline E'lat wave velocity, $\mathrm{m} / \mathrm{s}$ & $10.45 \pm 2.79$ & $11.10 \pm 3.12$ & 0.213 \\
\hline A'lat wave velocity, $\mathrm{m} / \mathrm{s}$ & $10.33 \pm 2.18$ & $10.90 \pm 3.18$ & 0.242 \\
\hline E/E'lat ratio & $7.67 \pm 2.52$ & $7.35 \pm 2.80$ & 0.489 \\
\hline E/E’mean ratio & $2.56 \pm 3.10$ & $2.85 \pm 3.06$ & 0.592 \\
\hline E’septal wave velocity, m/s & $7.2 \pm 1.79$ & $7.8 \pm 1.83$ & 0.385 \\
\hline A'septal wave velocity, $\mathrm{m} / \mathrm{s}$ & $10.02 \pm 2.27$ & $9.64 \pm 2.14$ & 0.319 \\
\hline E/E’septal ratio & $11.45 \pm 3.45$ & $10.24 \pm 3.50$ & $0.046^{*}$ \\
\hline IVRT, $\mathrm{m} / \mathrm{s}$ & $98.32 \pm 21.89$ & $95.13 \pm 19.80$ & 0.409 \\
\hline
\end{tabular}

ED+, with erectile dysfunction; ED-, without erectile dysfunction; LVSD, left ventricular systolic diameter; LVDD, left ventricular diastolic diameter; LVEF, left ventricular ejection fraction; RWT, relative wall thickness; PWT, posterior wall thickness; LVMI, left ventricular mass index; LAVI, left atrial volume index; E, mitral inflow early diastolic velocity; A, mitral inflow late diastolic velocity; E'lat wave velocity, lateral annular early diastolic velocity by tissue Doppler imaging; A'lat wave velocity, lateral annular late diastolic velocity by tissue Doppler imaging; E'septal wave velocity, septal annular early diastolic velocity by tissue Doppler imaging; A'septal wave velocity, septal annular late diastolic velocity by tissue Doppler imaging; IVRT, isovolumetric relaxation time.

cular disease, with the penile vasculature a particularly sensitive marker of systemic disease. The specific mechanism is thought to be due to increased levels of angiotensin II, which contributes to systemic hypertension and has been demonstrated in the corporal blood of hypertensive rats. Increased angiotensin II levels cause a subsequent increase in reactive oxygen species, which in turn reduces nitric oxide levels via a scavenging mechanism [24].
It is now well known that CKD is a risk factor for CVD [25]. Endothelial dysfunction is an early marker of CVD, and it has also been reported to occur in CKD patients $[26,27]$. In addition, endothelial dysfunction is a cause of $\mathrm{ED}$, because nitric oxide production from the endothelium decreases in this state. Therefore, it is not surprising that ED frequently occurs in CKD patients. Furthermore, consistent with our patients (all with MS), CKD patients 
Table 4. Multiple linear regression analysis with IIEF score as the dependent variable and LVH, MS, diastolic dysfunction, impaired renal function, albuminuria ( $A C R \geq 3$ ), and carotid plaques as independent variables

\begin{tabular}{|c|c|c|c|c|c|c|c|}
\hline Model term & Coefficient & SE & $\mathrm{T}$ & $\begin{array}{l}\text { Signi- } \\
\text { ficance }\end{array}$ & \multicolumn{2}{|c|}{$95 \% \mathrm{CI}$} & Importance \\
\hline $\mathrm{LVH}^{2}$ & 1.761 & 0.566 & 3.113 & 0.002 & 0.645 & 2.878 & 0.399 \\
\hline $\mathrm{eGFR}<60 \mathrm{~mL} / \mathrm{min} / 1.73 \mathrm{~m}^{2}$ & 6.207 & 1.626 & 3.818 & 0.0001 & 0.299 & 9.415 & 0.601 \\
\hline
\end{tabular}

LVH, left ventricle hypertrophy; MS, metabolic syndrome; eGFR, estimated glomerular filtration rate; SE, standard error.

often suffer from metabolic diseases such as hypertension, hyperlipidemia, and impaired fasting glucose. These metabolic abnormalities also cause endothelial dysfunction and are risk factors for ED as well as CVD. Therefore, in addition to the concomitant metabolic diseases, CKD per se appears, at least in some part, to cause ED via the induction of endothelial dysfunction.

The limitations of this study were the lack of penile duplex Doppler ultrasonography, at least in patients with ED based on the IIEF. Also, testosterone serum concentrations were not measured.

\section{Conclusions}

In this study, the presence of ED was associated with chronic myocardial injury, such as hypertrophy, or impaired renal function, indicating that ED is a probable marker of CVD and the need to take preventive measures towards it. Hence, patients with ED are advised to undergo both urological and cardiovascular examinations to improve not only their sexual health, but also their overall health and survival.

\section{References}

1 Nunes KP, Labazi H, Webb RC: New insights into hypertension-associated erectile dysfunction. Curr Opin Nephrol Hypertens 2012;21:163-170

2 Defeudis G, Gianfrilli D, Di Emidio C, et al: Erectile dysfunction and its management in patients with diabetes mellitus. Rev Endocr Metab Disord 2015;16:213-231.

3 Vlachopoulos C, Terentes-Printzios D, Ioakeimidis N, et al: Prediction of cardiovascular events and all-cause mortality with erectile dysfunction: a systemic review and metaanalysis of cohort studies. Circ Cardiovasc Qual Outcomes 2013;6:99-109.

4 Esposito K, Ciotola M, Giugliano F, et al: Mediterranean diet improves erectile function in subjects with the metabolic syndrome. Int J Impot Res 2006;18:405-410.

5 Biebel MG, Burnett AL, Sadeghi-Nejad H: Male sexual function and smoking. Sex Med Rev 2016;4:366-375.

6 Fung MM, Bettencourt R, Barrett-Connor E: Heart disease risk factors predict erectile dysfunction 25 years later: the Rancho Bernardo Study. J Am Coll Cardiol 2004;43:1405-1411.

7 Burris AS, Banks SM, Carter CS, et al: A longterm, prospective study of the physiologic and behavioral effects of hormone replacement in untreated hypogonadal men. J Androl 1992; 13:297-304.
8 Rosen R, Altwein J, Boyle P, et al: Lower urinary tract symptoms and male sexual dysfunction: the multinational survey of the aging male (MSAM-7). Eur Urol 2003;44:637649.

9 Araujo AB, Durante R, Feldman HA, et al: The relationship between depressive symptoms and male erectile dysfunction: cross-sectional results from the Massachusetts Male Aging Study. Psychosom Med 1998;60:458-465.

10 Feldman DI, Cainzos-Achirica M, Billups KL, et al: Subclinical vascular disease and subsequent erectile dysfunction: the Multiethnic Study of Atherosclerosis (MESA). Clin Cardol 2016;39:291-298.

11 Lavie CJ, Patel DA, Milani RV, et al: Impact of echocardiographic left ventricular geometry on clinical prognosis. Prog Cardiovasc Dis 2014;57:3-9.

12 Muntner P, He J, Hamm L, et al: Renal insufficiency and subsequent death resulting from cardiovascular disease in the United States. J Am Soc Nephrol 2002;13:745-753.

13 Chronic Kidney Disease Prognosis Consortium; Matsushita K, van der Velde M, Astor $\mathrm{BC}$, et al: Association of estimated glomerular filtration rate and albuminuria with all-cause and cardiovascular mortality in general population cohorts: a collaborative meta-analysis. Lancet 2010;12;375:2073-2081.
14 Lee M, Gardin JM, Lynch JC, et al: Diabetes mellitus and echocardiographic left ventricular function in free-living elderly men and women: the Cardiovascular Health Study. Am Heart J 1997;133:36-43.

15 Kannel WB, Gordon T, Castelli WP, et al: Electrocardiographic left ventricular hypertrophy and risk of coronary heart disease: the Framingham study. Ann Intern Med 1970;72: 813-822.

16 de Simone G, Palmieri V, Bella JN, et al: Association of left ventricular hypertrophy with metabolic risk factors: the HyperGEN study. J Hypertens 2002;20:323-331.

17 Carabello BA: The relationship of left ventricular geometry and hypertrophy to left ventricular function in valvular heart disease. J Heart Valve Dis 1995;2:132-139.

18 Drazner MH, Dries DL, Peshock RM, et al: Left ventricular hypertrophy is more prevalent in blacks than whites in the general population: the Dallas Heart Study. Hypertension 2005;46:124-129.

19 Rosen RC, Cappelleri JC, Smith MD, et al: Development and evaluation of an abridged, 5-item version of the International Index of Erectile Function (IIEF-5) as a diagnostic tool for erectile dysfunction. Int J Impot Res 1999; 11:319-326. 
20 Nagueh SF, Appleton CP, Gillebert TC, et al: Recommendations for the evaluation of left ventricular diastolic function by echocardiography. J Am Soc Echocardiogr 2009;22:107133.

21 Levey AS, Stevens LA, Schmid CH, et al: A new equation to estimate glomerular filtration rate. Ann Intern Med 2009;150:604-612.

22 Kakkavas A, Tsioufis C, Tsiachris D, et al: Erectile dysfunction and target organ damage in early stage of hypertension. J Clin Hypertens 2013;15:644-649.
23 Heikkilä A, Kaipia A, Venermo M, et al: Relationship of blood pressure and erectile dysfunction in men without previously diagnosed hypertension. J Sex Med 2017;14:13361341.

24 Jin L, Lagoda G, Leite R, et al: NADPH oxidase activation: a mechanism of hypertension-associated erectile dysfunction. J Sex Med 2008;5:544-551.
25 Suzuki E, Nishimatsu H, Oba S, et al: Chronic kidney disease and erectile dysfunction. World J Nephrol 2014;3:220-229.

26 Mesquita JF, Ramos TF, Mesquita FP, et al: Prevalence of erectile dysfunction in chronic renal disease patients on conservative treatment. Clinics (Sao Paulo) 2012;67:181-183.

27 Malyszko J: Mechanism of endothelial dysfunction in chronic kidney disease. Clin Chim Acta 2010;411:1412-1420. 